\title{
Exploring Students' Learning Needs: Expectation and Challenges
}

\author{
Dwi Poedjiastutie $^{1} \&$ Rhonda Oliver ${ }^{2}$ \\ ${ }^{1}$ University of Muhammadiyah Malang, Indonesia \\ ${ }^{2}$ Curtin University of Australia, Australia \\ Correspondence: Dwi Poedjiastutie, University of Muhammadiyah Malang, Indonesia. E-mail: \\ dpoedjiastutie@yahoo.com
}

Received: August 17, 2017 Accepted: September 11, 2017 Online Published: September 13, 2017

doi: 10.5539/elt.v10n10p124 URL: http://doi.org/10.5539/elt.v10n10p124

\begin{abstract}
Needs analysis is not new in education or academic circles. Many scholars and educators in different parts of the world see this approach as a valuable tool for program development and review as it is a mechanism that can be used to link the students' present academic learning with their future needs. This is also true with respect to language programs - the focus of the current study. At the target university, which is located in Indonesia, students are taught English following an ESP approach. Despite the program being in existence for 22 years, it is apparent there are problems with it as upon graduation many students have achieved only minimal English proficiency. To explore why this might be occurring the current study was undertaken using a mixed methods approach, specifically, large-scale, quantitative data was obtained using surveys circulated to 1000 students. This was complemented by qualitative data obtained from focus group discussions. The findings from the analysis of these two components are presented in the current paper. The findings show students at the target university have pragmatic reasons for learning English. Those include international collaboration, better life opportunities, business establishment international employment competitive, better international test outcomes, cultural awareness, and understanding English journals and books.
\end{abstract}

Keywords: need analysis, ESP (English for Specific Purposes), learning goals, ESP challenges

\section{Introduction}

Needs analysis (NA) is not new in education or academic circles. Many scholars and educators in different parts of the world see this approach as a valuable tool for program development and review as it is a mechanism that can be used to link the students' present academic learning with their future needs. This is also true in the case of language programs. A fundamental part of a NA entails the inclusion of learners' perspectives. This is because learners invest their time, money, and energy into learning, with the expectation that their investment will worthwhile. Because it is so important to understand language learners' needs, a great deal of NA research has been conducted and done so in a variety of contexts and using different methodological approaches. For example, Hyland (1997) used a closed questionnaire to survey 1619 students from eight disciplines at five Hong Kong tertiary institutions. Hyland's study revealed that students generally saw the value of English for Academic Purposes (EAP) classes as they recognize that proficiency in English is an important determinant of academic success in an English-medium learning environment. However, the students' perspectives on the need for language instruction varied according to their proficiency level, discipline and year of study. The findings indicated that less proficient students attached more importance to English classes than their more linguistically competent counterparts. Another finding was that the students' problems were centred on their productive skills writing and speaking, and also the acquisition of specialist vocabulary.

Evans and Green (2007) also conducted a large scale survey to undertake a NA in Hong Kong. They found a significant percentage of the students they surveyed experienced difficulties when studying content subjects through the medium of English. The evidence suggests that students' problems centred on academic writing (particularly style, grammar and cohesion) and academic speaking (particularly grammar, fluency and pronunciation). The findings also indicated that students' receptive and productive vocabularies were generally inadequate. Academic listening appeared to present students with fewer difficulties than writing, speaking and reading. What also emerged from this study was a picture in which inadequate basic language competence resulted in a lack of confidence as students struggled to accomplish complex tasks. This almost certainly gives 
rise to an urgent need for improved language skills among this student body.

Other studies have used both qualitative and quantitative data collection tools. Ho (2014), for instance, conducted a study to evaluate English for Specific Purposes (ESP) courses and the types of English skills needed by the computer science students at a university in Hong Kong during Science Internships. Ho did this by using a questionnaire that included both open and closed answers. Descriptive statistics (mainly frequencies) were used to analyse the quantitative part of the questionnaire, whereas the open-ended questions were analysed using content analysis, through which "fairly simple classifications or tabulations of specific information" (Borg \& Gall, 1989, p. 520). The findings suggested that the course should cover the reading and writing of emails, and that report writing, oral presentation and meeting skills should be retained in the course. Further, the students indicated they needed help in many areas, but they acknowledged that it was difficult to cover all the skills and communicative situations in a relatively short ESP course. Therefore, it was recommended that the duration of the ESP course be extended or an additional course could be offered.

Other NAs undertaken from a student perspective have focused on specific skills such as speaking and listening skills (e.g., Ferris \& Tagg, 1996; Ferris, 1998) and writing skills (e.g., Afzali \& Fakharzadeh, 2009; Casanave \& Hubbard, 1992; Huang, 2010; Jenkins, Jordan \& Weiland, 1993). For instance, Huang (2010) reports on a research project designed to assess undergraduate and graduate students' language-learning needs in the context of a new academic language support centre at a Canadian university. A total of 432 students and 93 instructors of English as an Additional Language (EAL) responded to questionnaires which asked them to rate the importance of academic writing. The findings indicated that there was much overlap in the skill items identified as being 'very important' by the graduate and undergraduate students and the instructors. However, students' self-assessment of their own writing skills and instructors' assessment of their students' writing skills differed dramatically.

Therefore, as indicated, NAs have a lot to offer language programs, particularly those that require significant improvement. Thus the present study undertakes NA within a specific teaching context, namely an English Department in a university in Indonesia, where top-down policies regarding the teaching of ESP have been implemented seemingly without due consideration given to the needs of the students. Therefore, a particular focus of this study, are those needs as identified by the students themselves.

\subsection{ESP and the Current Context}

As an area of instruction, ESP has been steadily growing since its inception in the 1960s. In fact, because of the influence of globalization ESP has become a key player in English language teaching. With its focus on learner needs, the link between ESP and NA is clearly apparent. In fact, NA is and always will be an important and fundamental part of ESP (Gatehouse, 2001; Graves, 2000). It is 'the corner stone of ESP and leads to a focused course' (Dudley-Evan \& St. John, 1998, p.122).

ESP is a core program for all freshmen enrolled at the target Indonesian university where the current study was conducted. It is focused on equipping students for both academic life and for their careers upon graduation. As indicated in the university's mission statement, the ESP program aims to provide English skill development so that students can read and comprehend English text books, journals, and articles in their disciplines. In addition, by undertaking this course, students can develop their spoken and written English communication skills. Over two semesters in their first year of study, students must take ESP courses depending on their majors (e.g., students from the Mathematics Department study English for mathematic purposes and students from Biology Department study English for Biological purposes). Further, students undertake courses in all four macro skill areas of English - specifically reading and speaking ( 2 courses each) and listening and writing (1 course each). These courses are all taught following an ESP approach.

Despite the program being in place for 22 years at the target university, upon graduation many students have been found to have problems with their English, struggling to engage in even simple English conversations. Anecdotally many report having insufficient English to enable their smooth transition into the work force where English is increasingly required. However, to date no systematic evaluation has been conducted at the target university, particularly with regard to the learners' own perceptions. Thus it is the aim of this study to do so. Therefore, the current study seeks to answer the following research questions:

1) In their own perception, what are the English language needs of students?

2) Are these needs currently being met?

\section{Methods}

A mixed method approach was utilized in this study. Specifically, the current research involved a combination of 
a large-scale questionnaire, containing closed questions, complemented by qualitative data derived from Focus Group Discussions (FGDs).

\subsection{Participants}

The participants in this study were students drawn from that group enrolled in the ESP program at the target university when the study was conducted, representing all the different majors. Firstly surveys were circulated to 1000 students and of these, 284 students from 12 departments returned their individual questionnaire (i.e., $28.4 \%$ return rate).

In terms of the background of the survey participants, they came from 18 provinces across Indonesia. The majority $-64.7 \%$ or 186 of the respondents - were from East Java. 165 or $58.09 \%$ were females, 90 or $31.69 \%$ were males, and 29 or $10.21 \%$ provided no information about their gender.

The majority of the survey participants (210 or 73.94\%) had not learnt English prior to enrolment, with only 53 of the participants (18.66\%) having previously attended an English course. Another 21 participants (7.39\%) did not give any information in this regard.

Students from the target university were also invited to participate in FGDs. Three focus groups were formed and each consisted of eight volunteer students. This number was chosen as this is considered to be the optimum number for focus group research (Fraenkel, Wallen, , \& Hyun, 2012) The sample was drawn from all faculties (Faculty of Health Science, Faculty of Teacher Training and Education, faculty of Engineering, Faculty of Economic and Commerce, and Faculty of Social and Politics). The participants were aged 18-22 years and 13 were female and 11 male. 78\% were from East Java Province, 10\% were from Nusa Tenggara Barat Province, $5 \%$ were from Kalimantan, another 5\% were from West Java, and 2\% were from Bali.

\subsection{Procedure}

The first step of this study involved the circulation and collection of the survey. This occurred at the end of the semester. The survey papers were distributed after the final examination papers. It was explained to the students that even though their participation was voluntarily, it was very important to have their voice heard to enable improvements to the ESP program to be made in the coming years.

The data from the surveys were analysed using descriptive statistics with the responses calculated as percentages. The advantages of doing this is that it is easy to understand (especially for the target audience of English teachers and policy makers).

Next participants were invited to participate in the FGDs. This was done by way of an announcement made to students in all faculties through their ESP teachers. Students who were interested in attending, registered their names with a staff member who coordinated the ESP at the university. Participants were then randomly selected (numerically) and notified about the arrangements for the discussion. The researcher led the discussions. Initially it was planned that the discussions would be conducted in English. However, since not all students were sufficiently fluent in English, Bahasa Indonesia was used. Each discussion took two hours per group.

Next, transcriptions were done immediately after each discussion was completed. All the recordings were transcribed in regular orthography as the focus was the content not linguistic analysis. All the transcriptions were then checked by a second person to ensure they were correct.

The first step of analysis involved reading the text data over and over to gain an initial impression of the data. Next the themes that emerged were colour coded by hand in order to get a closer look at the data and to gain a strong feel for it. In doing so the researcher read in depth and used a 'think-aloud' strategy (Fraenkel, et.al, 2012) before and during coding of the transcripts.

The emergence of the themes or categories was done through the process of data redundancy. Data redundancy is a method that enables the sorting out of unimportant information so that only information which directly answers the research questions is retained (Fraenkel et al., 2012).

\section{Findings}

Based on the analysis of the survey and focus group discussions several specific needs were identified, namely that students felt it important to be able to communicate in English so that they can: 1) be competitive in the employment market, 2) be able to participate in international collaboration, 3) improve their learning outcomes (e.g. undertake the TOEFL), and 4) improve their life opportunities. In addition, the participants strongly supported the need for the ESP program. Each of these findings is discussed in turn. Before presenting the students' specific needs and learning goals and to contextualise the study, the students' perceptions on the ESP Programs as part of their compulsory curriculum is described first. 


\subsection{The Students' Views about the ESP Program at the Target University}

The first question of the survey examined whether or not the students at the target university wanted to study ESP. The survey result (see Table 1 below) showed that most - $252(88.78 \%)$ claimed that they were eager to learn English in the ESP program, with only 5.98\% saying 'No' and 5.28\% students not sure.

Table 1. Needs for ESP

\begin{tabular}{ll}
\hline Needs of ESP & Number of Respondents and Percentage Agreement \\
\hline Yes & $252(88.73 \%)$ \\
No & $17(5.98 \%)$ \\
Not Sure & $15(5.28 \%)$ \\
\hline
\end{tabular}

This result reflects a sentiment that emerged in the FGDs where almost all the student participants indicated their belief that English has an important role to play because it is an international language. Furthermore they claimed that they did not feel any extra pressure having ESP as a mandatory subject in their curriculum. For example:

No, I don't feel pressured. I'm happy with the ESP program. Before I came to this university, my English was not that good, but after learning it for one semester my English is better than before (Student NV).

The next series of questions in the survey explored which components of the ESP course the participants rated as the most important. Note, the way the survey was constructed allowed them to select more than one skill in their responses.

The results show 203 out of $284(71.47 \%)$ students indicated that mastering speaking was most important. Next, $47.18 \%(\mathrm{n}=134)$ indicated that they thought grammar was an important aspect to learn. Over one-third of the respondents or $37.32 \%(\mathrm{n}=106)$ agreed on the importance of both listening and writing skills. Whereas only 85 out of 284 students (approximately 30\%) indicated that increasing their English vocabulary was the most important. A similarly small percentage $(28.87 \%)$ of students indicated it was reading that was important .These results are presented in the following table.

Table 2. English skills

\begin{tabular}{ll}
\hline English Skill Courses & Number of Respondents and the Percentage Agreement \\
\hline Speaking & $203(71.47 \%)$ \\
Grammar & $134(47.18 \%)$ \\
Writing & $106(37.32 \%)$ \\
Listening & $106(37.32 \%)$ \\
Vocabulary & $85(29.92 \%)$ \\
Reading & $82(28.87 \%)$ \\
\hline
\end{tabular}

Again these findings from the survey were reflected in what emerged from the FGDs. During the discussions most of the students suggested that developing their speaking skill is their primary goal. They described several reasons for this. The first and most-cited reason is because of increasing globalization (i.e., internationally English is the most accepted medium of communication) and specifically because of the approaching Asia Free Trade Area (AFTA) agreement. Some students described how they wanted to be able to develop relationships with people from countries outside Indonesia and they understood that being able to communicate well in spoken English was a key way of achieving this. In particular they saw it as a vital step for success in their future careers. Although it was clear from the range of responses that being able to communicate orally in English is a key student need, what appeared less clear from the participants' responses is how this might be achieved. One participant did express the belief that people should start to learn a language by speaking it, not simply by developing an understanding of grammatical knowledge:

When I was learning English in junior high school, we just learnt about grammar, and we couldn't speak. It's so 
difficult to speak if we only learn grammar in the first place. I learnt to communicate first by feeling confident to speak in English (Student AZ).

Other students highlighted the difficulty they had encountered when learning English, particularly during their high school years. They indicated that although it is a compulsory subject in Indonesian high schools, the way it is currently being taught means that their ability to communicate orally is not well developed. They attributed this to the focus given to grammar. They described how students are required to memorise many grammatical patterns rather than being encouraged to learn how and when to use them. That is, a great deal of language teaching in high schools focuses on the form of the language, rather than developing the students' fluency in speaking it. For example, one student described it this way:

I think we have been studying English since we were in elementary school, but we still need to master English. It's an international language.... English is a must do subject. I will feel happy if I am able to speak it, but now I feel frustrated that I can't express particular ideas that I want to say. I really want to be able to speak as fluently as English speaking people (Student RN).

A number of other students also expressed a belief that by being able to communicate in English fluently, other people will attribute positive characteristics to them. In this way it is a skill that will advantage them in their career.

Other students also described how they would like teachers to make it a priority to equip them with the necessary oral communication skills, instead of simply teaching grammar. The reasons they provided for this included their belief that language is learnt for the purpose of communication and that it is not learnt by heart. In a similar vein, another participant described how people express ideas through speaking not through grammar. Yet another participant described her belief that just learning English through the teaching of grammar presented obstacles when trying to speak. Another participant went further suggesting that having a more communicative approach would make English classes easier and more fun.

In addition to general oral communication skills, within the FDGs a number of students indicated that they wanted to master different types of English skills. For example, one said that it was her belief that listening was the most important skill to master first. She suggested that this is because being able to listen well provides a model of how to speak appropriately. Other suggested a desire for greater focus on vocabulary development, for example:

For me the most important thing to develop is vocabulary. Having a lot of words will help me with my speaking and in the long run it will also improve my listening and reading (Student ES).

Unlike the results from the survey data, where nearly half the participants gave support for grammar teaching, the participants in the FGDs suggested that grammar was not one of their priorities when learning English. There was only one student who described grammar as being important:

Grammar is the skeleton of language. If we don't understand the grammar we won't be able to speak (Student $T W)$.

In fact, as described above, in the FGD many students' lamented their inability to communicate well in English which they attributed to their learning experiences at high school where there was a grammar focus.

Instead of prioritising grammar, the majority of the FGD participants described how they thought reading was the skill that students were hoping to develop in the ESP program. One reason for this is, as described in the following extract, that reading is a strategy that can be employed to develop vocabulary:

I like reading best since reading enriches my vocabulary. I understand what the paragraph is about so that I can answer the comprehension questions quite easily (Student RN).

\subsection{The Students' Goals of ESP Learning}

Based on the survey responses several specific goals and purposes for English learning were identified. Table 3 provides a summary of these results: 
Table 3. English learning goals

\begin{tabular}{lll}
\hline English Learning Goals & $\begin{array}{l}\text { Number of } \begin{array}{c}\text { Respondents } \\
\text { Percentage Agreement }\end{array} \\
\text { and }\end{array}$ \\
\hline To participate in overseas training and scholarship program & $126(44.36 \%)$ \\
To have better life opportunities such as traveling, using more & $122(42.96 \%)$ \\
sophisticated technology & $109(38.38 \%)$ \\
To establish business with overseas people. & $94(33.09 \%)$ \\
$\begin{array}{l}\text { To be able to work in prestigious international } \\
\text { companies/institutions }\end{array}$ & $92(32.39 \%)$ \\
To improve TOEFL and IELTs scores. & $68(23.94 \%)$ \\
To be able to understand English speaking people and cultures & $61(21.47 \%)$ \\
To be able to read and understand English journals and books.
\end{tabular}

Furthermore the qualitative data derived from FGDs provides further support for the findings emerging from the survey as described below. .

Just less than half of the survey participants (i.e., $n=126$ or $44.36 \%$ ) indicated that they hoped their ESP course would help them to collaborate internationally. Within the FGDs the participants elaborated this further describing how they wanted to develop their English competence to enable them to take up positions with international companies, businesses and organizations. They indicated that such organisations require applicants to have a high level of English competence, especially in the oral language area and, therefore, this was what they wanted to achieve from doing the ESP course.

Others described how they hoped developing their English communicative competence would enable them to gain a place in one of the educational overseas programs. One such program, Erasmus Mundus is very popular with students at this target university. Freshmen enrolled at this university see older students returning from their overseas study (as part of this program), and expressed a desire to have similar experiences. On this basis, a number described how they hoped their ESP teachers could direct their teaching towards this goal and equip them to be able to achieve this. For example:

Of course, I have goals for ESP here. I want to develop myself and increase my skills in speaking. I want speak like a native speaker. And with that skill I can go around the world. I want to get a scholarship to the Julliard School in New York. I am really obsessed with the Julliard School in New York. It's like a school of Music. So that's my goals (Student AM).

Of the survey participants $38.38 \%(\mathrm{n}=109)$ hoped that ESP learning would support their business interactions with people overseas. Within the FGDs the participants elaborated this further describing how nowadays businesses cannot be restricted to just one country. If they wanted to expand their business interests, they will need to explore opportunities overseas. And this, of course, requires them to master English as many countries now have chosen this language a lingua franca. For example:

My brother-in-law has a very successful business here in Indonesia and wanted to expand it overseas. Many overseas guests come and are interested. Unfortunately, his English is not that good so it takes a while to develop his business and this does mean a loss of opportunities (Student RN)

A considerable proportion $-42.96 \%(n=122)$ of the survey participants indicated their desire for the course to improve their life opportunities, such as supporting them as they travel and helping them to be able to use more sophisticated technology. The FGD participants elaborated on this describing how developing their English will improve their life opportunities including being able to use English manuals of instruction when they purchase new technology. They also described how it would help them build networks with overseas people and to use English websites and other resources from the internet. In addition, many of the FGD participants described how developing their English would help them as they travel and they saw this as improving their life opportunities:

Of course I have goals for ESP. I want to develop myself and increase my skills in speaking. I want to speak like a native speaker. And with that skill I can go around the world (Student AM).

One third of the survey participants $(n=94)$ indicated that they hoped the ESP course would help make them competitive in the employment market. In the FGD many of the participants said that when they commenced 
tertiary study they had hoped that the ESP course would focus more on effective communication rather than developing knowledge about the language because they felt it was important to enable them to successfully compete for jobs. For example:

I want to work for the United States Peace keeping scheme. My brother told me that in the next five years the military needs personnel who both possess English and computer skills (Student YD).

Others indicated that they also required English competence for business communication. Clearly the important role of English in their future careers was well understood by the students.

A similar proportion $(32.3 \%, \mathrm{n}=92)$ in the survey indicated that the wanted the course to help improve their learning outcomes, for example to be able to successfully undertake the TOEFL test. In the FGDs, the participants also described how they wanted to achieve satisfactory results in TOEFL - in fact, it was one of the students' primary expectations when learning English. Some students even described how they expected teachers to show them strategies for successful TOEFL test taking:

I want ESP to teach us the trick (strategy) of listening, speaking, and writing because for me English is important for my future, like the TOEFL test, to make questions and to answer the questions because I want to know the trick for doing that (Student TP).

The results of the survey showed that to understand English speaking people and cultures was the goal of 23.94\% $(\mathrm{n}=68)$ participants. The FGD participants also described a similar sentiment. Further a number described how they wished their teachers would provide more English teaching materials with stronger cultural content. Others said that developing their understanding about the beliefs and ways of thinking of English speaking people may help them avoid communication breakdown. Some even indicated their own belief that learning about various cultures would make them wiser:

"None of the cultures in the world are the same; we are different from others, so understanding this makes us richer and wiser" (Students HD)

Developing their English to help them understand English journals and books was supported by $21.47 \%$ (61) survey participants. It was also an expectation shared by the participants in the FGDs. They asserted that many new books that they wished to read, either for educational or entertainment purposes are written in English. In this way having English competence will open their mind to expanded learning opportunities:

"I think if you are students, your main responsibility is learning, right? So if you can't understand English how can you expand your knowledge gain?" (Student AM)

\section{Discussion and Conclusion}

Although the stated objectives of the ESP program at the target university is English skill development so that students can read and comprehend English text books, journals, and articles in their disciplines, from the findings it is evident that although some expressed the desire to improve their English test scores and to be better able to read in English, students see the English learning as being beyond just educational goals. They indicated that they studied English to enable them greater life opportunities, especially in terms of international collaboration. They also hope that by developing their English proficiency they will be competitive in the job market. They also want English so they can better understand the cultures of those who speak English. These are similar to the findings of several other studies (e.g., Brunton, 2009; Chaudron et al., 2005; Chew, 2005; Edwards, 2000; Genghesh, 2013; Holliday, 1995; Kaur \& Lee, 2006; Yu \& Xiao, 2013).

In order to fulfil the needs identified by the students, teachers will need to have or develop the teaching capacity to do so. For example, one of the goals of ESP is to develop their English reading skills so they are better able to read English journals and books once admitted into higher education, but this places a considerable responsibility on teachers to provide the appropriate pedagogy to achieve this, a task made even more difficult given the time constraints of the courses available (i.e., only two semesters). This challenge is exacerbated by the apparent limited English proficiency of some of the teachers (Poedjiastutie \& Oliver, 2017). If teachers do not have the necessary skill themselves, then it is an unrealistic expectation for them to help students.

In a similar way, although the students indicated that they want more opportunities to develop their oral communication skills, the way the current ESP pedagogy is organised means it is difficult for this need to be met. Currently many of ESP classes at the target university and, in fact, throughout Indonesia provide only a minimum amount of spoken English exposure (Wati, 2011). This is despite the main aim of ESP classes being to prepare learners 'for chosen communicative environments' (Mohan, 1986) and especially for using 'language in context' (Lorenzo, 2005). Clearly for this need to be met, change is required in Indonesian ESP classrooms, not 
only in terms of teaching practice, but also in the way that English is assessed. If only reading, writing and grammar are the main components evaluated, then these elements will be the focus of the teaching program. However, a shift to assessing students' oral proficiency (and setting the bench mark at a sufficiently high level) may lead to a greater focus on this aspect within the ESP program.

Not only does it seem that ESP teachers struggle in terms the requirements of the ESP curriculum, it also appears that many students are not yet ready for ESP since their English is not yet at a level to support the ESP learning. In the broader context of Indonesia, English is not used in daily communication and most people have limited exposure to the language even though they may have studied it at school and at the tertiary level. This situation is made even more challenging because the target university, as is the case in a number of higher education institutions Indonesia, accepts a large number of high school graduates with very low levels of English. Consequently teachers report reverting to teaching a lower level of general English rather than ESP due to students' low English ability (Marwan, 2009). As Marwan recommends, this an urgent problem that needs to be addressed.

Another factor that that presents challenges in meeting the self-identified needs of the students is the inconsistency of their behaviour. Almost all the student participants indicated their belief that English has an important role as an international language, yet most students who participated in the FGDs claimed that they did not feel any pressure having the ESP course as a mandatory subject. This was supported by classroom observations (see Poedjiastutie \& Oliver, 2017) where it was noted that students' learning behaviours were less than desirable (e.g., they were unpunctual, seen playing with the mobile phones, and generally appearing disengaged with the learning tasks). Of course, it may well be that the teaching strategies and approaches being used were not sufficiently motivating and this is something that also may need to be addressed.

Where English is a foreign language, such as in Indonesia, it can be very difficult for language learners to find opportunities to use it for communicative purposes because the society does not use it for daily interactions. Yet wider exposure to English would give students greater opportunities for using and, therefore eventually learning the target language. For example, this can be done by teachers inviting native speakers or expatriates who are living locally to come to their classes. Some exchange students from different parts of the world at this university could also be invited to share their experiences and description of their cultures in English. Such activities could be conducted either regularly or as an incidental part of the program. This would be particularly effective for speaking and listening classes as models of English would then be provided by such classroom guests. In addition, teachers could invite some English school teachers, English courses instructors, parents who are able to speak English etc. to functions held for students at UMM. The more opportunities the teachers can create for students to hear English spoken and use their own English skills, the more confident students will become.

Although a number of pedagogical implications have been outlined, it must be acknowledged that this study has a number of limitations. In the quantitative section, one of the concerns is the limited number students who responded to the questionnaires ( 284 of 1,000 or $28 \%$ ). An increase in the response rate would provide more reliable and valid results. Enabling the researcher to select the best time in the academic calendar for surveying the students (rather than at the end of the academic year as was the case in the current study) and the use of pre-mailings, follow up contacts, incentives, or combination of several procedures are recommended for future research in order to attract potential participants.

In addition, this present study was conducted only with students at the target university. It would be useful for further research to investigate the perceptions of students and other stakeholders in and outside the university (e.g., principals of high schools, the directors of English courses, the chairpersons in other educational institutions, and the managers of language centres). For example, surveying students at other universities would allow comparisons to be made and thereby providing a wider picture of the situation in Indonesia. It was also mean that the English learning needs that exist in other institutions could be ascertained.

In conclusion, whilst the students at this target university have mostly pragmatic reasons for learning English, to address these needs English teaching at this university may need to be modified. Specifically the capacity of teachers may need to be improved and pedagogy adapted to fully address the students' needs.

\section{References}

Afzali, K., \& Fakharzadeh, M. (2009). A needs analysis survey: The case of tourism letter writing in Iran. ESP World, 22(1).

Borg, W., \& Gall, M. (1989). Educational research: An introduction (5th ed.). New York: Longman.

Brunton, M. (2009). An account of ESP - with possible future directions. English for Specific Purposes, 3(24). 
Casanave, C. P., \& Hubbard, P. (1992). The writing assignment and writing problems of doctoral students: Faculty perceptions, pedagogical issues, and need research. English for Specific Purposes, 11, 33-49. https://doi.org/10.1016/0889-4906(92)90005-U

Chew, S. K. (2005). An investigation of English language skills used by new entrants in banks in Hong Kong. English for Specific Purposes, 24(4), 423-35. https://doi.org/10.1016/j.esp.2005.02.004

Chaudron, C., Doughty, C., Kim, Y., Kong, D., Lee, J., Lee, Y., ... Urano, K. (2005). A task-based needs analysis of a tertiary Korean as a foreign language program. In M. Long (Ed.), Second Language Needs Analysis (pp. 225-261). Cambridge: Cambridge University Press. https://doi.org/10.1017/CBO9780511667299.009

Dudley-Evans, T., \& St John, M. J. (1998). Developments in English for specific purposes. Cambridge: Cambridge University Press.

Edwards, N. (2000). Language for business: Effective needs assessment, syllabus design and materials preparation in a practical ESP case study. English for Specific Purposes, 19(3), 291-296. https://doi.org/10.1016/S0889-4906(98)00029-5

Evans, S., \& Green, C. (2007). Why EAP is necessary: A survey of Hongkong tertiary students. Journal of English for Academic Purposes, 6, 3-17. https://doi.org/10.1016/j.jeap.2006.11.005

Ferris, D. (1998). Students' views of academic aural/oral skills: A comparative needs analysis. TESOL Quarterly, 32(2), 289-318. https://doi.org/10.2307/3587585

Ferris, D., \& Tagg, T. (1996). Academic oral communication needs of EAP learners: What subject matter instructors actually require. TESOL Quarterly, 30(1), 31-58. https://doi.org/10.2307/3587606

Fraenkel, J., Wallen, N., \& Hyun, H. H. (2012). How to design and evaluate research in education (8th ed.). Boston: McGraw Hill.

Gatehouse, K. (2001). Key issues in English for specific purposes (ESP) curriculum development. Internet TESL Journal, 7(10).

Ghenghes, P. (2013) Students and teachers of engineering speak out! What do you really need? Arab World English Journal (AWEJ), 4(1), 11- 27.

Graves, K. (2000). Designing language courses: A guide for teachers. Boston, MA: Heinle \& Heinle.

Ho, B. (2014). Communicating in English during computer science internships. International Journal of Humanities and Social Science, 4(7), 314-330.

Holliday, A. (1995). Assessing language needs within an institutional context: An ethnographic approach. English for Specific Purposes, 14(2), 115-126. https://doi.org/10.1016/0889-4906(95)00006-D

Huang, L. (2010). Seeing eye to eye? The academic writing needs of graduate and undergraduate students from students' and instructors' perspectives. Language Teaching Research, 14(4), 517-539. https://doi.org/10.1177/1362168810375372

Hyland, K. (1997). Is EAP necessary? A survey of Hong Kong undergraduates. Asian Journal of English Language Teaching, 7, 77-99.

Jenkins, S., Jordan, M. K. J., \& Weiland, P. O. (1993). The role of writing in graduate engineering education: A survey of faculty beliefs and practices. English for Specific Purposes, 12, 51-67. https://doi.org/10.1016/0889-4906(93)90027-L

Kaur, S., \& Lee, S. H. (2006). Analysing workplace oral communication needs in English among IT graduates. English for Specific Purposes World, 1(12).

Lorenzo, F. (2005). Teaching English for specific purposes. Retrieved from http://www.usingenglish.com/articles/teaching-english-for-specific-purposes-esp.html

Marwan, A. (2009). ESP teaching challenges in an Indonesian vocational higher institution. The English Teacher, $38,1-12$.

Mohan, B. A. (1986). Language and Content. Reading, MA: Addison-Wesley.

Poedjiastutie, D., \& Oliver, R. (2017). The English Learning Needs of ESP Learners: Exploring stakeholder perceptions at an Indonesian University. Teaching English as Foreign Language in Indonesia, 28(1), 1-21.

Wati, H. (2011). The effectiveness of Indonesian English teachers training program in improving confidence and motivation. International Journal of Instruction, 4(1), 79-104. 
Yu, X., \& Xiao, Y. (2013). A Course Design Guideline for Legal English Teaching in Chinese Tertiary Education: From the Perspective of Content-based Instruction. Theory and Practice in Language Studies, 3(7), 1123-1128. https://doi.org/10.4304/tpls.3.7.1123-1128

\section{Copyrights}

Copyright for this article is retained by the author(s), with first publication rights granted to the journal.

This is an open-access article distributed under the terms and conditions of the Creative Commons Attribution license (http://creativecommons.org/licenses/by/4.0/). 